\title{
Normativity and Reality in Peirce's Thought
}

\section{Serge Grigoriev}

\section{OpenEdition}

\section{Journals}

Electronic version

URL: http://journals.openedition.org/ejpap/512

DOI: 10.4000/ejpap.512

ISSN: 2036-4091

\section{Publisher}

Associazione Pragma

\section{Electronic reference}

Serge Grigoriev, "Normativity and Reality in Peirce's Thought », European Journal of Pragmatism and American Philosophy [Online], VI-1 | 2014, Online since 08 July 2014, connection on 17 March 2020. URL : http://journals.openedition.org/ejpap/512 ; DOI : https://doi.org/10.4000/ejpap.512

This text was automatically generated on 17 March 2020.

\section{(c) (1) $\odot$

Author retains copyright and grants the European Journal of Pragmatism and American Philosophy right of first publication with the work simultaneously licensed under a Creative Commons Attribution-

NonCommercial-NoDerivatives 4.0 International License. 


\title{
Normativity and Reality in Peirce's Thought
}

\author{
Serge Grigoriev
}

1 The purpose of the essay is to explore some points pertaining to Peirce's conception of reality, with a special emphasis on the themes developed in his later writings (such as normativity, common sense, and the logic of signs). The resulting proposal advances a preliminary reading of some key issues (arising in connection with Peirce's discussions of reality and truth), configured with a view to the socially sustainable, coordinated practices of inquiry that are intrinsically embedded in the biological and cultural dynamics of the evolving sense of reasonableness in human practical and cognitive enterprises.

2 When philosophers talk about "reality," it usually helps to distinguish between some customary senses of the term, so as to avoid the unnecessary confusion. The following two conceptions deserve a mention here on the account of their customary meanings: reality as the totality of all that is or may be, regardless of our ability to experience it; and reality as the sum total of our actual and possible experiences - let's call it "phenomenal reality." There is a third sense of reality, which is of principal concern to us here - because it is the one most congenial to Peirce - namely, reality as the aspect of the world represented in true beliefs which the inquiry ultimately aims at. This brief essay will not bother much with the totality of what may be "out there," apart from all possible experience, ${ }^{1}$ hence, its primary task consists in clearing up the distinction between the third sense of reality, which happens to be of a special interest to pragmatists, and the phenomenal reality.

3 The latter may be conceptualized as a largely informal and abstract projection, depicting the field of conceivably possible experiences based on the sampling of actual experiences that have been registered thus far. Phenomenal reality presents itself in the form of experiences, and is, therefore, always at least partially constituted by 
thought. This thought, however, is usually neither deliberate nor rigorously structured: experiences just strike us as being roughly of a certain kind. Because of this, phenomenal reality is often simply thought of as "external reality" - that which impinges, or is capable of impinging, on us by way of experience. As such, it is determinable in countless ways, yet it is never fully determinate. ${ }^{2}$ Reality in the sense pursued here, on the other hand, is something deliberately constructed in the light of inputs from the phenomenal world, so as to produce the sense of a reasonable totality. Accordingly, when one uses the term "real" correlatively with this latter sense of "reality," one does not mean something merely external or perceptible; instead, the meaning of the word "real," here, can be more properly assimilated to that of "true," with the proviso that, because our grasp of reality and truth is never complete, what is meant thereby is something like "roughly true."

Reality, then, is a rationalization of the field of experience, represented in true beliefs which together provide the direction for reasonable thought. Reasonable thought, in turn, is the kind of thought that represents the world as intelligible or, perhaps more precisely, hospitable to the purposeful existence of reasoning beings. Such a view, moreover, is congruent with the positions advanced in the familiar Peircean literature.

5 Peirce himself, of course, directly challenged the assumption that reality must be understood as independent of thought (CP 5.430, 1905); in his view, we can only know the "human aspect" of things, and that is "all the universe is for us" (Peirce 1911, 43). ${ }^{3}$ That reality must be further understood as an intended product of constructive thought is suggested, for example, by Rosenthal's discussion of the distinction between occurrence and fact $(1994,5-6)$, where facts emerge as the result of a deliberate analysis of occurrences. Reality, then, as Rosenthal explains, is constituted as a consistent system of facts (ibid., 2-3), i.e., reality is ultimately existence as analyzed. When Rosenthal says that the "world is dependent upon the meaning system that grasps in a way in which reality as independent is not" (ibid., 7) and is, ultimately, the "ideal of a complete synthesis of possible experience" (ibid., 8), she means by "world" what is here meant by "reality;" and by "reality," what is here meant by "phenomenal reality."

Peirce's view of fact as something abstracted from experience (CP 6.67, 1898) is also emphasized by Hookway, who underscores the important and indissoluble connection between the constitution of facts and the accepted practices of inquiry in relation to which alone facts can acquire their proper meaning (Hookway 2000, 90-1). ${ }^{4}$ And a somewhat related point can be made in connection with Misak's view that "it is misleading to talk of the truth as being the complete description of the world" (1991, 149). Moreover, according to Misak, a description merely aspiring to completeness would not do at all, for not only should the eventually attained belief "fit harmoniously" with the other parts of our knowledge $(2010,87)$, such beliefs must additionally possess epistemic virtues such as "fecundity, simplicity, and the like" $(1991,82)$.

7 Hence, the ultimate description of reality is less about comprehension understood in terms of coverage, and more about generating a particular style of thought, distinguished by a number of intellectual virtues. As Peirce puts it: "thought is of the nature of a sign. In that case, then, if we can find out the right method of thinking and can follow it out - the right method of transforming signs - then truth can be nothing more nor less than the last result to which the following out of this method would ultimately carry us." (CP 5.553, 1906.) $)^{5}$ Reality, then, may be usefully thought of as the 
object of knowledge, with knowledge understood as properly functioning thought, while the nature of what that means, or what it means to be that, is being worked out continuously in truth-conducive inquiries.

8 At the same time, one must not be tempted to expect the eventual absorption of phenomenal reality into thought. The view defended here is realistic in the sense indicated by Hausman when he insists that what is real must be "to some extent or in some way independent of mental construction" (1993, 144). The experience always contains "the residue of what is never exhausted by interpretation in any finite time" (ibid., 156). In other words, it always contains the real possibilities of the development of our present experience in ways that we do not presently anticipate.

Two further ideas need to be introduced at this point. The first is concerned with the normative themes of Peirce's later work. Some scholars find his reflections on the topic too vague to be of any real use, yet Peirce himself considered them to be incredibly important, and his system without them - radically incomplete (Maddalena 2010, 262). His position is understandable for, without these considerations, it is not clear what the purpose of inquiry should be, nor what form its final fruits should take. Logical consistency or rapport with experience may seem like self-evident desiderata; however, on the one hand, they are insufficient to delimit the ultimately desirable perspective, and on the other, they are (in turn) also vague - how much consistency and at what price? What sort of rapport? It seems that such questions can only be answered or even posed legitimately only in conjunction with some conception of an ideal form of life, based on and conducive to a certain right manner of thought. According to Peirce, the purpose of inquiry is to develop "degrees of self-control unknown to primitive man" (CP 5.511, 1905-8), enabling us to develop appropriate rules of conduct, and to improve these rules through subsequent criticism (CP 5.533, 1905-8). The end of inquiry, then, must consist in establishing a certain form of life, a way of thinking and existing in the world in accordance with the best that we know. But what is best? Self-mastery according to Peirce should be exercised to render human life "beautiful, admirable" (Peirce 1909, 36). The ground of preference, then, is ultimately esthetic (ibid.).

10 Peirce's definition of esthetic ideal as that which is admirable in itself (CP 1.612, 1903; CP $2.199,1902)$ is not immensely helpful; however, he provides us with a more substantial clue when he describes the sense of esthetic fulfillment in terms of "intellectual sympathy, a sense that here is a Feeling that one can comprehend, a reasonable feeling" (CP 5.113, 1903). In fact, along with logic and ethics, esthetic sensibility bears witness to the intrinsic reasonableness of the world, confirming, in the sensuous modality, our intellectual intuition that "general principles are really operative in nature" (CP 5.101, 1903). ${ }^{6}$ Provided this much, it seems possible to credit Peirce with something like a Kantian view of esthetic ideal.

11 According to Kant, the esthetic experience of beauty attests to the harmony between mind and nature (CJ \$42, 5:300), ${ }^{7}$ comprehended in explicitly moral terms. Human beings want to see some evidence that the universe is responsive to their cognitive and moral needs (CJ, Introduction, 5, 184), and these needs, in turn, are understood by Kant primarily in terms of a consistent exercise of moral autonomy. To lead a dignified 
existence, we need to act according to a set of rules, which would enable us, without sacrificing consistency and integrity, to maximize the opportunities for acting in accordance with our best judgment, instead of merely yielding to the brute force of contingent circumstances. To the degree that we succeed in actively leading a life instead of being pushed around by it, we can be said to be free. Accordingly, aesthetic experience suggests to Kant that the lawfulness of nature may harmonize with our pursuit of freedom or moral autonomy in accordance with the dictates of our reason (CJ, Introduction, 5, 176). It is in this sense that nature, through esthetic contemplation, shows itself to be reasonable. Is it too much of a stretch to think of Peirce's esthetic ideal of concrete reasonableness in terms of preconditions for the meaningful exercise of rational autonomy? If not, then, we must reckon with the esthetic constraint thus understood in thinking about the shape that our inquiries must take.

And this leads, rather naturally, to the second consideration. Peirce asks: "But what is esthetically good? Perhaps we may say the full expression of an idea? Thought, however, is in itself essentially of the nature of a sign. But a sign is not a sign unless it translates itself into another sign in which it is more fully developed. Thought requires achievement for its own development, and without this development it is nothing. Thought must live and grow in incessant new and higher translations, or it proves itself not to be genuine thought." (CP 5.594, 1903.) The purpose of rational existence, then, must be, in part, to create the conditions most favorable to the perpetuation and development of thought.

Unlike a material object, consciousness per se has no staying power; it cannot abide. Thought is the primary mode of the endurance of consciousness, and, through its endurance, thought acquires reality: it begins to matter, begins to generate consequences. The mode of endurance appropriate to a substance - namely, identity in the case of thought is replaced by the mode of endurance appropriate to an event namely, continuity (and a generative, dynamic continuity, at that). The mode of the endurance of thought, and the constitutive condition of its reality, is the mechanism of representation, which, if understood properly, includes interpretation as one of its constitutive moments. To continue to exist, in other words, a thought needs to be carried on, it needs to be put forth, and picked up, and bounced back: the thought remains real only so long as the thought, or one of its derivations, is in play. This is, in fact, what Gallie once called Peirce's "most characteristic and fundamental philosophical insight:" that thought and the sign that expresses it, be it a formula or a sentence, "is essentially something to be developed, something that requires or calls for development" (Gallie 1966, 46). To stay alive, a thought needs to be repeated, and, to be repeated effectively, it needs to be challenged, corrected, amplified, retold... "There is no exception," says Peirce, "to the law that every thought-sign is translated or interpreted in a subsequent one, unless it be that all thought comes to an abrupt and final end in death." (W 2,224, 1868.)

14 The proper business of philosophy, then, is logic broadly construed - that is, the study of the methods for properly developing the pertinent consequences of signs or thoughts. Thoughts, in the non-psychological sense of the word, exist in the form of signs, and a sign, according to Peirce, is "an object which is in relation to its object on the one hand and to an interpretant on the other in such a way as to bring the interpretant into a relation to the object, corresponding to its own relation to the object." (Peirce 1904, 11.) In other words, the logic of representation that governs the 
genesis and circulation of signs incorporates essentially two distinctive yet intertwined functions: a referential function, insofar as a sign always points to its subject matter, ${ }^{8}$ and a communicative function, insofar as a sign is always addressed to someone, calling for a response. Hookway expresses a similar point when he says that there are two questions with which semiotic concerns itself: how can thoughts and sentences represent reality, and how can inquirers collaborate within a community $(1992,119)$ ?

The communicative aspect of the problem must be dealt with in the context of what Peirce calls his "social theory of reality" (CP 6.610, 1893). It is in being corrected by others that we first encounter the notion that reality is independent of one's private opinion, learning, consequently, to associate the idea of truth with that which "would stand in the long run" in the course of critical public deliberation (W 2,239, 1868). Participation in rational discourse, i.e., in the only form of life that assures to thought a stable prospect of orderly development, requires an assumption that one may be willingly compelled to come to an agreement when presented with sufficient argumentation. Acceptable forms of argumentation, of course, are governed by public norms; but so are the acceptable forms of evidence. Discourse, as Misak rightly claims, can only remain rational so long as it remains evidence-sensitive (1991, 60); and evidence is always evidence not only of something but also for someone prepared to recognize it as such.

The notion of agreement attained in the process of rational inquiry, in turn, is related to the distinctly problematic notion of convergence. Thus, Peirce declares: "Different minds may set out with the most antagonistic views, but the process of investigation carries them by a force outside themselves to one and the same conclusion... No modification of the point of view taken, no selection of other facts for study, no natural bent of mind even, can enable man to escape the predestinate opinion." (W 3,273, 1878.) Such language is liable to give rise to an idea of an invisible universal guiding order, which may be interpreted, for example, in terms of a "teleological tendency" towards "lawfulness and consistency" and "away from fragmentation" (Hausman 1993, 33) - or, say, in terms of "increasingly unified information" (DeMarco 1971, 26) collected by the inherent movement of evolutionary process (Mahowald 1973, 180). It is clear that Peirce was continuously drawn to something of this sort, even though it may appear as a piece of indefensible cosmological speculation. Some scholars are more sanguine about accepting Peirce's view for what it is. My own view is closer to that of Hookway, who points out that, since Peirce's "treatments of the topic generally have a throwaway character" $(2000,4)$, presented in a grand fashion as the predetermined destiny of thought, convergence remains "simply a metaphysical mystery" (ibid., 50-1).

Fortunately, Peirce occasionally approaches the issue in a more cautious spirit. Thus, as some scholars have convincingly argued (Misak 1991, 149; Sokolowski 1997, 82-3), it is ill-advised to confuse the contention that we should hope to find an answer to any wellformed question with the notion that we may ultimately arrive at some allencompassing final vision of the universe. Peirce himself makes a similar point: "We must look forward to the explanation, not of all things, but of any given thing whatever." (W 6,206, 1890.) Later he qualifies this with a cautionary warning that we should not even expect an answer to every specific question, because there are "real 
vagues, and especially real possibilities" (CP 5.453, 1905). Construed in terms of the success of concrete inquiries, the notion of convergence begins to sound much more promising. It becomes even more so, when we take into account the fact that Peirce frequently refers to the prospect of convergence even with respect to particular inquiries as merely a "hope" (W 3, 273, 1878, CP 6.610, 1893, CP 8.113, 1900), which prompts us to press on with our research. Hence, one may be warranted, after all, in provisionally setting the prospects of grand convergence aside, focusing instead on an analysis of particular episodes of convergence.

Thus, when two travelers set out for the same destination, assuming that it is a real destination and not a fruit of their fantasy, their search should terminate in a meeting, and the place of this meeting can be said to be preordained in virtue of their intentions. This terminus ad quem is that which corresponds to the declared purpose of their journey, in the same way that the correct answer corresponds to a well-put question i.e., by constituting a response that conclusively fulfills the aspiration declared at the outset. This meeting, of course, need not necessarily take place: the travelers may fail to reach their destination for various reasons. Yet, even if they meet, the fact of meeting by itself does not signify that the right destination has been reached. Mere agreement does not constitute the rightness of the answer; instead, the right answer serves as the basis of warranted agreement. Chance meetings abound, and so do gratuitous alliances of opinion.

Part of the reason to insist that the place of our meeting is determined beforehand by the nature of our search is to secure the sense that there is a place we ought to meet, so as to come together independently to an agreement of a very special sort - i.e., a rational agreement. One reason we may cherish the hope that this type of agreement is possible is that it testifies to the ability of our thought to pick out what is independently intended by the thoughts of another; in other words, it shows that we can truly share thoughts - which is a tad bit more than warmly holding hands. Would one be right to conclude, then, that rational thought aims at fulfilling the imperative of the social impulse? No, if by this is meant an increase in the sense of unity and belonging owing to the eliding of all disagreements and tensions. If rational thought is to serve the interests of sociality, its functioning must be understood in terms of transforming the kind of community that we strive for. It cannot be a community of universal assent, for in such a community, thought would cease. It cannot be a community preoccupied merely with the accumulation of certified results, because in accepting the same formula, people do not need to share the same thought; in fact, to accept and use a formula, one need not have any pertinent thoughts at all. Instead, it should be a community that pursues the development of reliable methods of inquiry and inference, promulgates the standards and strategies of effective argumentation, cultivates the skill of selecting and finding relevant evidence, and continues to improve its standards of what counts as a responsible and meaningful response to whatever conditions our shared experience. A community of this sort would progressively secure for its members the possibility of seeing what another person means, thereby securing the possibility of rational agreement or disagreement. Formation of such a community is, of course, in the interest of thought, because it assures the best chances of thought's continuous perpetuation and fruitful development.

What of convergence, then? As a hope or a regulative ideal (Hausman 1993, 134), it appears to mark the conditions under which the intentionality of thought can have 
public standing - meaning that others ${ }^{9}$ can grasp the content of one's thoughts, what one's thoughts are about, as opposed to, say, one's psychological states, or the words running through one's head. The idea of convergence, in other words, secures the conceptual possibility of several thoughts sharing the same subject matter, even in cases where this subject matter is not present but merely anticipated or suggested in actual experience. Furthermore, in guiding our inquiries, the putative (or idealized) projected convergence supplies the conceptual possibility of a sense of failure or success with respect to what we ought to think, allowing us to distinguish, at least provisionally, between better and worse modes of reasoning and research practices, laying thereby the potential foundations for a transition to a more rational type of community.

The notion of eventual convergence accomplished through the sheer accumulation of experience, as nature nudges us along, may seem attractive in theory, but in theory alone. To manage things is not to understand them; and, of its own accord, experience merely reminds us what we must cope with, not what we must learn from it. Yet, thinking of convergence in purely transcendental terms is also hardly satisfactory. We can attempt to think of it, then, as a theoretical projection based on the experience of what, for lack of a better term, may be called the experience of apparent convergence: i.e., a perfectly routine experience of two or more investigators arriving at the same result, with this result withstanding further examination by other investigators, at least for the time being. Thus, when we agree that it is raining outside, anyone who cares to check is bound to concur with our view. We could turn out to be wrong: provisional convergence is merely apparent, and as such, it is more of a convergenceeffect. Its genuineness is intrinsically defeasible. Yet, it is quite enough to give one a concrete sense of what a genuine convergence would be like - to hope that it may, in fact, be attainable through pursuing the inquiries that scholars are engaged in, and to foster a preference for research strategies that tend to consistently produce such episodes of apparent convergence. We need no more, provided that we are prepared to admit that our trust, here as elsewhere, may well be misplaced.

Returning to the topic of the relationship between representation and reality, it is possible to broach the issue by considering Peirce's distinction between immediate and dynamical objects. The dynamical object corresponds roughly to the subject matter of thought; the immediate object is the way in which the subject matter is represented in the sign or thought. A dark cloud on the horizon is the immediate object of my thought, but the dynamical object, or the subject matter, of my thought is not a dark cloud but whatever presently appears to me as a dark cloud; should it turn out to be a swarm of locusts, the immediate object of my thought would change, but the dynamical object, or subject matter, will remain the same - for, all along, my eyes and thoughts were fixed on the swarm, which in my thoughts got provisionally assimilated to the image of a cloud. The dynamical object is that to which our thought is directed; yet it is always directed under some more or less specific guise, under a concept, a designation, in short, a sign. Our interpretation is always directed at the dynamical object (the subject matter), but it always attaches to an immediate object (a provisional identification). ${ }^{10}$ 

primarily a referential rather than an attributive function. My mention of a dark cloud, despite being descriptively mistaken in the end, still pegs the subject matter under consideration, since it succeeds in directing your gaze towards the phenomenon intended. The immediate object is a "hint" or mark by which the dynamical object is indicated (Peirce 1908, 31), while the dynamical object itself cannot be predicatively specified, and can only be grasped by the interpreter with the help of "collateral experience" (CP 8.3 14, 1909). The reason for this is that the dynamical object (the subject matter of our inquiry) is the object "regardless of any aspect of it, the object in such relations as unlimited and final study would show it to be" (CP 8.183, undated), while predication is necessarily restricted to some specifiable aspect of the subject matter under consideration. That is precisely the sense in which the dynamical object (or subject matter) "is exactly that about which more can be learned" (Short 2007, 199); it is never exhausted by our present understanding of it. Provisional identification, from this perspective, merely aids us in designating or hypostasizing the object of inquiry (cf. ibid., 268).

On the other hand, it is necessary to note a contrary point: namely, that the function of the provisional identification is never merely referential, for it is also, in an important sense, attributive. Thus, while a provisional identification may fail to rightly specify the appropriate attributes of the dynamical object, it nonetheless directs our inquiry along a certain path, which may be more or less promising. The immediate object may be just a handle by which we attempt to pick up the object, but the object itself is, in the end, just so many handles by which we may try to pick it up. As Hausman points out, one cannot think of the goal of our inquiries as an "extra-conceptual condition of interpretation" or a thing-in-itself $(1993,27)$. It can only be thought insofar as it is already related to thought - through a provisional identification that both points to the object and suggests a direction in which further determinations may be gainfully sought.

Is there a point at which the interpretive process can be said to have reached its terminus? If we started out by observing a fast-moving dot and, having tracked it consistently, identified it as a car, we may be entitled to reject all further skepticism as contrived. External reality has forced its verdict on our senses: the car has proved itself to be a car. This sounds convincing, but such predominance of brute externality unfortunately underplays the role of thought in constituting its subject matter: the car would reveal itself to be a car no matter what one previously thought about it. Suppose, instead, that from the rapidly advancing cloud of dust emerged a slow-moving turtle. We must accept the turtle for what it is - it crawls right past our feet; but would we not be plagued by a suspicion that the subject matter (the dynamical object) of our attention has changed, that we were really tracking something else? It seems quite plausible that, on such an occasion, we would be asking ourselves what it was, in fact, that we have been tracking, instead of blissfully accepting the turtle as the whole answer.

Thoughts are occasioned by something external, yet the identity of an external condition is predicated on our ability to intelligibly reconstitute the continuity between the provisional identifications of what it was that our thoughts have been about. A radical discontinuity in one's provisional conceptualizations of dynamical object tends to undermine one's faith in the continuity of reference. The external 
counts as the real only with the proviso that there is some hope of such (conceptual) continuity being restored - for example, through an attribution of an intelligible perceptual error. A radical and unexplainable discontinuity in perception suggests a breakdown of the ordinary apparatus of reference. If my cat turns into a palpable elephant upon eating some cereal, the sorry state of my mental faculties is really the only elephant in the room.

This brings up an important point: external is only real (potentially) insofar as we are entertaining some hope of successfully (and, better yet, reliably) directing our own and (better yet) one another's thought towards it. External reality, then, is not something that merely forces itself upon us, but whatever forces itself upon us in ways that are, at least in principle, amenable to reason. In this sense, the true mark of the real is not, contrary to the ordinary view, that we are ineluctably responsive to it (we are responsive to delirium and madness), but that it is responsive to our attempts at reasoning about it. The sociable nature of intelligible thought works, here, as a check against the brute force of individual experience. External reality, in short, is that element of the external that tends to respond to our purposeful mental efforts - by either reinforcing or frustrating them in roughly intelligible ways. It is not the universe, but merely the element of reasonableness within it.

Concern with the enduring continuity of reference sheds light on yet another interesting subject: the function of vagueness in reality-oriented discourse. A vague sign, unlike a general sign, does not by itself specify the criteria of its correct application; it intrinsically calls for further conceptual elaboration (CP 5.447, 1905). As such, it merely waves in the direction of its intended object without providing us with a secure grasp on it. Yet, Peirce insists that vagueness is not a defect in thinking ( $\mathrm{CP}$ $4.344,1905)$, and "is no more to be done away with in the world of logic than friction in mechanics" (CP 5.512, 1905). Part of the point is pragmatic: "perfect accuracy of thought is unattainable," and overstrained efforts at rigor and clarity routinely result in greater confusion (Peirce 1903, 4). But more importantly, vagueness has a distinctively positive function in the conceptual economy of research. By being intrinsically indeterminate, a vague designation invites contextually sensitive codetermination, wherein we exercise our judgment in light of realistically obtaining pragmatic considerations (Hookway 2000, 58-9). Since such specific determinations are never fully binding and, at least in principle, infinitely revisable, the evolution of a vague term may continue indefinitely, with each new permutation seen as an extension of its originally intended meaning, intrinsically related to and at least partially implied in the things that have been already said about it. Development of meaning over time, as Putnam observes, is capable of reflecting not merely a change in the use of words, but changes in interpreting our ways of life $(1995,302)$.

The significance of this point emerges when one compares the development potential of a vague versus a general term. A general term is surely capable of evolving as we gain a progressively better understanding of its area of proper application. The key distinguishing feature of a vague term in this regard is merely the fact that it can simultaneously support a number of incompatible developments or determinations. This is why most logicians find vague terms to be particularly troublesome. One must, then, think of some positive function that can be served by courting such conceptual confusion. It does not seem implausible to claim that such a function may be related to the sheer versatility permitted by allowing the proliferation and coexistence of 
partially incommensurable interpretations. Such versatility, of course, introduces considerable slack into the system, inevitably loosening the sense of what counts as an appropriate interpretation of the same subject matter. The sacrifice of clarity results somewhat paradoxically in the increased stability of discourse: we are permitted ample resources for continuously improvising connections that establish a sense of intelligible continuity between the new determinations forced upon us by the new experience and changing practice and earlier provisional determinations through which the subject matter of our discourse has been fixed thus far. Vagueness, in other words, permits one to retain a sense of the continuity of reference through a series of radical conceptual innovations. This point is ostensibly related to the point made by Rosenthal when she says that common sense provides "the vague criterion of the shared meaningfulness and sense of workability of incommensurable scientific theories" $(1994,16)$. The essential vagueness of common-sense concepts is their most remarkable logical characteristic; yet, within the framework of Peirce's common-sensism, such concepts provide an indispensable foundation for inquiry.

Philosophers have long tended to think of externality in terms of correspondence, and present observations may shed some light on how the meaning of this term can be most gainfully construed. ${ }^{11}$ External reality to which we are answerable cannot be seen as thought-independent. In fact, its distinguishing mark qua intelligible externality consists in its responsiveness to reasoning and reason-guided action. It need not pander to our preconceptions, yet, even in frustrating them, it needs to leave some traces from which the intelligibility of our error may be, in principle, restored. What matters then is not so much the clarity of vision, but a sense of continued interaction and contact - a retention of the sense of a long-inhabited conceptualized space that supports a particular field of practice by supplying its subject matter, which, however vaguely and changeably specified, in virtue of this very vagueness and imprecision, never leaves us for long with the feeling that it has completely eluded our grasp or receded beyond it. Through all the permutations of "matter," despite false starts and enduring aberrations, physics never entirely loses touch with it subject matter - the material world - at the crudest level of understanding.

31 Relating the idea of externality to the inventive maintenance of a field of practice grounded in the common subject matter belonging to the realm of shared experience (possible or actual) provides one with a number of advantages that the classical view of correspondence sorely lacks. Most importantly it allows one to avoid the idea of correspondence or confrontation without interpretation, wherein the lucky propositions home in on some mysteriously pre-conceptual data to claim a destined match. Instead, one can simply talk of sentences (say, of atomic theory) rightly interpreted in accordance with a set of established discursive practices (of, say, physics), suitably announced in conjunction with certain experiences (say, instrument recordings), elicited through some coordinated procedures belonging to the field of practice, and interpreted in accordance with the standard reporting protocols of this practice. The sense of correspondence here is an artifact of successfully coordinated practices, which mediate a sense of effortless continuity within the specified theoryexperience complex. One could, then, hazard a guess that metaphysical intuitions about correspondence are merely an extrapolation of the concrete instances of correspondence effects, which tie together and result from the successfully coordinated practices of the sort we have described. Effects of convergence, then, can be further explicated in terms of correspondence thus understood: two practices converge whenever they succeed in 
systematically eliciting some results or predictions recognized as equivalent in accordance with the standard interpretive procedures of both practices.

The approach outlined here, with respect to both of these key notions, can be underscored nicely by Skagestad's suggestion that truth or reality is "beyond any actual experience; still it can be given a meaning by extrapolation from the experience of that finite process by which scientists have so far reached agreements, and of experimental procedures involved in that process." $(1981,83$.$) Hence, it stands opposed$ to the transcendental approaches, such as Apel's, whereby one thinks of truth as the "idealization" worked out from the viewpoint of an "an indefinite and unlimited community of researchers" (2004, 45-6). The danger of the latter type of approach, in my opinion, is that we may find ourselves engaged in the pointless project of determining "what the relationship between truth and inquiry would be if inquiry were something it is not" (Misak 1991, 154).

While the considerations discussed thus far suggest some pointers with respect to the likely conditions of rational inquiry, they are somewhat too general to provide a sense of the governing dynamics of inquiry in the long run. To attempt a little clarity on this front, one may want to look at the conditions of inquiry that are, in a qualified sense, extra-logical. Specifically, one may want to think about the role of the common sense, as the ground for the routine confidence that we do have a basic grip on our experience, as well as the conception of the aesthetic impulse, which urges the inquirers to seek the types of explanation possessing certain architectonically desirable traits.

There is something distinctive about the role that our common-sense beliefs perform in providing us with a feeling of groundedness in the shared world. Yet, ordinarily understood, our common-sense beliefs are too varied and too disorderly to provide any definitive clue as to why that actually is the case. One may want to look instead for some deeper shared common-sense structures and, unless one does so, it may not be easy to make sense of Peirce's contention that there may be a "fixed list" of commonsense beliefs "the same for all men" (CP 5.509, 1905). If, however, one were to agree to make an assumption that our ordinary common-sense beliefs could be seen as modified and particularized expressions of an underlying set of some (nearly) universally shared beliefs, then what Peirce had in mind becomes readily apparent. Those common-sense beliefs would, indeed, "vary a little and but a little under varying circumstances and in distant ages" (CP 5.444, 1905).

One can further note that, according to Peirce, common-sense depends on "the total everyday experience of many generations of multitudinous populations" (CP 5.522, 1905). Hence, common sense can change and grow: it does not simply arise at one point as a new characteristic feature of our biological endowment. However, it changes but little, suggesting either a biological mode of transmission or the presence of a very strong empirical constraint on the prospects of the viability of alternative theoretical conjectures that can be plausibly made at this level of cognitive operation. The difference at stake is one between a genetic and a cultural mode of transmission: in either case, however, universally shared common sense must be seen as a product of an externally constrained convergent development. 

$(2004,40)$, without speculating about the exact genesis of common-sense beliefs. Hookway, meanwhile, is inclined to trace them to some innate conceptions such as space, time, and force, accounted for, in turn, by the work of natural selection (2000, 167). This approach may appear to be promising, in part because Peirce's one-time friend, evolutionary philosopher Chauncey Wright, had articulated precisely such a view - known in the pertinent literature as "functional apriori" - wherein the primary categories of thought emerge as the product of the action of natural selection upon subsequent generations of human beings aiming to fruitfully cope with experienced environment. Peirce himself mentions that we have "from birth some notions, however crude and concrete, of force, matter, space, and time," as well as "some notion of what sort of objects their fellow-beings are, and of how they will act on given occasions." (W $4.450,1883$.) Misak further cites some textual evidence suggesting that we could rightly describe both abductive reasoning $(1991,98)$ and the "generalized ideal of good reasoning" or "instinctive logic" (ibid., 91) as products of evolutionary adaptation.

The evolutionary conjecture is further confirmed by Peirce's view that as we depart ever further from natural conditions that influenced the growth of the mind, the guiding force of natural suggestion progressively wanes (W 8,100,1891). As we abandon conditions resembling the "primitive mode of life," our vague common-sense beliefs cease to be indubitable (CP 5.445, 1905) and, one would imagine, become increasingly unreliable. This is, of course, one of the reasons why common-sensism always has to be critical, taking its cue from common sense, but scrutinizing it rigorously and setting conventional beliefs entirely aside when necessary (Hookway 2000, 179). Furthermore, generally, one can expect the helpful direction from common-sense beliefs to be limited almost entirely to the sphere of practical adaptation (Short 2007, 344), where selective pressure can exercise its influence.

The picture, however, is somewhat more complicated for, even as he acknowledges the diminished usefulness of "natural light" as we "advance further and further into science," Peirce maintains, nonetheless, that its glimmer, however faint, remains indispensable in recommending to us hypotheses that "make upon us the impression of simplicity" since "the existence of a natural instinct for truth is, after all, the sheetanchor of science" (CP 7.220, 1901). Perhaps one should say "nothing new:" in fact, we have "a natural bent in accordance with nature's," because our interactions with nature over generations, have so to speak, bent us that way (CP 6.477, 1908, and CP $1.121,1896)$. One could even explain how an instinctive mode of thinking, developed under the conditions of practical struggles for survival, could be of help in the most exquisite theoretical reaches of science.

Think of a painter, for example, whose eye is trained by looking at the polymorphous abundance of natural forms. Now set before her eyes an abstract composition. It is not of nature; it is contrived. And yet, the painter may judge it as being natural, as having life, or as being strained and lifeless. What "naturalness" designates here is a sense of a prevailing mood, which sets the proportions of various defining relationships, in such a way as to endow the manifold with a definitive type of complex unity, so as to make it feel "right," "simple," or plausible. Failure to capture a sense of natural qualitative order, then, would be experienced as a disturbance of sensibility, as somehow awkward, difficult, or poorly digestible. Construed thus, the intuition that gives us a sense of what theory is more worth pursuing would have to be understood in negative 
terms, producing a vague sense of awkwardness and disturbance whenever we are presented with something that violates the natural composition to which we have become unconsciously inured.

While all this may indeed be so, it is also clear that, for Peirce, the truth-instinct also has a positive, actively guiding, enticing, or beckoning role. It is the element of reasonableness in the universe "to which we can train our own reason" (CP 5.160, 1903), and the active voice here seems to indicate that this element is positively perceived and sought, rather than being gradually forced upon us through instinctive avoidance of physical or intellectual distress. There are at least two sound considerations for why a demand for such an "attractive" element, preceding punitive selection, may plausibly make sense.

41 One is that natural selection has to operate on something: being a selection, it cannot invent and is, therefore, powerless to promote adaptation unless favorable variations continue sporting in a relatively frequent and sustained fashion. In the sphere of thought, mistaken possibilities are endless, while the effects of truth and error (under primitive conditions) are considerably shielded from the selective pressure. (Being wrong and fast would normally be better than being right but slow.) The mind cannot evolve adequate conceptions of even the most fundamental categories, unless it happens to be from the start more or less apt to form conceptions of a potentially successful sort. We must start with something like a "scent for the truth" (CP 6.531, 1901) before we can be pressed to develop the very rudiments of the mental apparatus that makes our concern with truth, however unconscious, an operative element in the struggle for survival.

Hence, there is a clear point to Peirce's worry that if "there be nothing to guide us to the discovery," we would "have to hunt among all the events in the world without any scent" (W 3,317, 1878) - a futile undertaking and, potentially, a dangerous one. The tendency to make the right connections, of the sort that is required for the productive work of natural selection to take off, need not be anything elaborate. We merely need a tendency for the mind not to wonder aimlessly for too long, spinning connections ad libitum, capriciously, or in accordance with the order of stimuli that has little relation to causal order. Once such a tendency is there, the natural selection can refine its flow over time; without such a tendency, it is not clear that we are entitled to speak of a mind in the first place.

The second consideration is of an historical sort, and pertains to the development of philosophy and science, both of which have largely been driven by an interest in reality as a rational structure, rather than a mere setting of the struggle for prosperity and survival. In fact, very frequently, concern with the more mundane interests was believed to obscure the greater philosophical truth, to result in a sense of intellectual myopia. Meanwhile, if one does construe common sense largely as a product of gradual adaptation, it makes sense to think of it as comprising strategies and notions designed to manage practical conundrums, and management requires bracketing things off and smoothing them over, reducing risks and clinging to the familiar. In other words, reliable management of external pressures encourages, to some degree, a closure of conceptual horizons, resulting in a warranted attitude of suspicion and distrust towards radical possibilities. Common sense, then, is theoretically conservative. Therefore, an interest in radical theoretical exploration must be guided by some other 
instinct, some other drive, which urges one to forgo practical considerations for the sake of intellectual or aesthetic satisfaction.

One could actually suppose that the very same primitive attunement to the scent of truth that lies at the origin of the evolution of common sense continues to operate independently in theoretical inquiries, wherein it is refined and elaborated not in accordance with the demands of external pressure, but in conformity with a sense of its own intrinsic normativity. One can think of it, for example, on the analogy with the language acquisition faculty, which, although incapable of generating a formed language on its own, enables the learning of language within a time-frame that would be unimaginable without such innate capacity.

One may also be warranted in following Peirce when it comes to identifying the input of this instinctual capacity in terms of feeling: a conceptual response to secondness in the areas where the established structures of thirdness provide no determinate guidance can only be based on a qualitative sense that certain ways of configuring the relationship at hand feel less right than others. It is also plausible to suppose that the dictates of this feeling are worked out most systematically and immediately in mathematics, regarded by Peirce as the first science requiring no foundations (Hookway 2000, 183). So mathematics would, then, be the prime discipline of developing one's aesthetic sense, giving concrete form to one's premonitions of reasonableness.

Peirce's interest in normativity in his later work, when read in this key, appears quite natural, as does his estimation of his prior work as radically incomplete without it (Maddalena 2010, 262). Reality, as a view of the world suffused with reasonableness, cannot simply be informed by the external pressure of experience - it requires instead an active reconstruction of this experience in accordance with the progressively articulated ideals of reasonableness developed in the light of considerations that can only bear a tangential relationship to the business of practical management and survival. This is why ideal norms "alone raise Humanity above Animality" (EP2: 465; 1913). Peirce's conception of aesthetic ideal also has to be understood in this context. Its foundation is not pleasure, but a kind of intellectual empathy with the world, which assures us that "general principles are really operative in nature" (CP 5.101, 1903) generating what Peirce calls "a reasonable feeling," i.e., a feeling that "one can comprehend" (CP 1903, 5.113). It is easy to see why Bernstein is inclined to draw an analogy between Peirce's conception of aesthetic and Plato's conception of Good (1971, 193-4), for, here the notions of beauty, goodness, and reason are all brought together, in the conception of the admirable or ideal. Attainment of this ideal, in turn, would permit "free development of the agent's own esthetic quality" (CP 5.136, 1903), thus giving a concrete sense to the idea of a free rational life admirably lived.

The aesthetic feeling, apparently, relates to the arrangement of parts within the whole (CP 5.132, 1903), so it is related to a sense of measure and proportion, to a sense of intellectual prosody, qualitatively experienced. My own preferred term for what is thus experienced is the "mood" of the presentation, deriving from Peirce's comment about the poetic mood "in which the present appears as it is present" (CP 5.44, 1903). Other designations are used by different commentators: "feeling tone" (Rosenthal 1994, 100), "suchness" (Hausman 1993, 126), and, most descriptively, the "firstness of a thirdness" (Hookway 1992, 174). Peirce, on one occasion, refers to this as "flavor sui generis" (CP $1.531,1903)$. The problem with endorsing such a feeling, as Hookway justly observes, is 
to "understand how standards adopted without justification can have objective validity" in such a way that they are "not psychologically determined but hold for all rational agents" $(1992,59)$. As Peirce observed with respect to logic, the (occasionally) felt compulsion may have its place, but it would be a grave error to reduce logicality to this compulsion (CP 3.432, 1896). The same would hold for an aesthetic ideal that, insofar as it belongs to the universe of firstness, is plagued by the additional problem of never being capable of "perfect actualization on account of its essential vagueness if for no other reason" (Peirce 1908, 30).

Peirceans are fortunate in that they do not have to be stumped by questions of this sort. One simply needs to ask what habits of thought and action the adherence to a particular ideal involves, and to appraise the consequences of such habits within their proper field of application. Pragmatism, then, provides a clear meaning for the notion that an ideal can be tested, supplying, in the bargain, a sense of what it may mean for an ideal to be compromised or improved. To the degree that my penchant for symmetrical structures leads me to significant discoveries that otherwise could not be made, my aesthetic feeling remains on the right track. To the degree that it makes me overlook significant effects of asymmetrical structures, my unconditional preference for it requires adjustment and curtailment.

One must not think, however, that our normative intuitions are not accountable to anything beside the theoretical consequences of their systematic deployment. Reality, as an ideal, is not only characterized by reasonableness, but also by sharedness, i.e. by its public character; hence, the consequences that we consider are always, at least in part, social consequences. Considerations pertaining to the conditions of social coexistence must have a due effect on one's reflexive musings about the appropriateness of her feelings. As Peirce puts it, "If conduct is to be thoroughly deliberate, the ideal must be a habit of feeling which has grown up under the influence of a course of self-criticisms and of hetero-criticisms; and the theory of the deliberate formation of such habits of feeling is what ought to be meant by esthetics." (CP 1.574, 1906.) Our feelings, then, are jointly answerable both to the sense of inner satisfaction and to the practicalities of social interaction, under the obtaining external conditions. Therefore, common sense has a rightful bearing on the continued appropriate development of the aesthetic instinct of reasonableness, which, in the course of evolutionary history, must have stood at its source.

This brings up, in turn, an important question about the permeability of the instinctive foundations of thought to cultural influence. On this score, the expression of aesthetic sentiment can be expected to be more malleable than common sense. This is so because it is a mere feeling or sensibility that has not undergone any specific determinations in the course of evolution; common sense, on the other hand, involves the formation at the biological level of some relatively specific structures or thought-categories that, like anything biological, must display a considerable resistance to modification and change. Biological evolution operates on the scale of at least thousands of years, so appreciable modification to the innate structures of common sense could be only affected by a fundamental change in conditions of existence, lasting over a sufficiently long period (biologically) to exert sufficient selective pressure. In that regard, the deep structure of common sense may well be shared between ourselves and our preliterate ancestors. 
51 The trade-off here is between development and stability. The base categorical framework of common sense provides us with a tried foundation for managing our ordinary interactions with external reality. As Peirce points out, "Our innate mechanical ideas were so nearly correct that they needed but slight correction" (W $4,450,1883)$. At the same time, this foundation does not suffice for the purpose of drawing precise distinctions valued by science, nor does it give us much direction in the areas far removed from the natural conditions of life. It can be virtually unerring, but only within its proper area of application; yet that is the foundation on which all other scientific inquiries are built (CP 5.522, 1905). The categories of common sense provide us with a structure that proved itself workable through the thick of evolutionary time: yet, it is only that - workable. It is by no means the final instance of truth. Yet, in functioning as our instinctive point of departure, it serves as a safety net for our theoretical and experimental enterprises; should they fail, we return to the ordinary frame of reference, where we are never completely at sea. Hence the curious dynamic between critical inquiry and common sense, involving "a complex interplay of intellectual reflection and trusting acquiescence in habitual judgments and sentimental responses" (Hookway 2000, 260). There is in culture a kind of biological inertia, ensuring that our relationship to experience at no point may end up entirely unworkable. There is a sense of reasonableness and aesthetic instinct, ensuring that we venture beyond what is necessary for mere comfort and survival. There is also the historically accumulated cultural capital of a given society at a given time, on terms of which these natural proclivities get filled out and fine-tuned within the span of an individual generation.

\section{BIBLIOGRAPHY}

APEL K. O., (2004), "Sense-Critical Realism: A Transcendental-Pragmatic Interpretation of C. S. Peirce's Theory of Reality and Truth," in J. De Groot (ed.), Nature in American Philosophy, Washington, DC, Catholic University of America Press, 37-52.

BERNSTEIN R., (1971), Praxis and Action: Contemporary Philosophies of Human Activity, Philadelphia, University of Pennsylvania Press.

DEMARCO J., (1971), “Peirce's Concept of Community: Its Development \& Change,” Transactions of the Charles S. Peirce Society 7, 24-36.

GALliE W. B., (1966), Peirce and Pragmatism, New York, Dover Publications.

HAUSMAN C., (1993), Charles S. Peirce Evolutionary Philosophy, Cambridge, Cambridge University

Press.

ноокWAY C., (1992), Peirce, New York, Routledge.

ноокWAY C., (2000), Truth, Rationality, and Pragmatism: Themes from Peirce, Oxford, Clarendon Press.

MADDALENA G., (2010), “The Belief Story: Peirce's Anti-Kantian open Perspectives," Revista de

Filosofia 11, 257-266.

European Journal of Pragmatism and American Philosophy, VI-1 | 2014 
MAGADA-WARD M., (2003), “As Parts of One Esthetic Total: Inference, Imagery, and Self-Knowledge in the Later Peirce," Journal of Speculative Philosophy 17, 216-223.

MAHOWALD M., (1973), “Peirce's Concept of Community: Another Interpretation,” Transactions of the Charles S. Peirce Society (9), 175-186.

MISAK C., (1991), Truth and the End of Inquiry: A Peircean Account of Truth, Oxford, Clarendon Press.

MISAK C., (2010), "The Pragmatic Maxim: How to Get Leverage on a Concept," The Harvard Review of Philosophy 17, 76-87.

PEIRCE C. S., (1932-1958), Collected Papers of Charles Sanders Peirce, Cambridge, MA, Harvard

University Press.

PEIRCE C. S., (1953), To Lady Welby, New Haven, Graduate Philosophy Club.

PEIRCE C. S., (1984-2009), Writing of Charles S. Peirce: A Chronological Edition, Bloomington, Indiana University Press.

PEIRCE C. S., (1998), The Essential Peirce, Vol. 2: Selected Philosophical Writings: 1893-1913, Bloomington, Indiana University Press.

PUTNAM H., (1995), "Pragmatism," Proceedings of the Aristotelian Society 95, 291-306.

RoSenthal S., (1994), Charles Peirce's Pragmatic Pluralism, Albany, NY, SUNY Press.

SHORT T. L., (2007), Peirce's Theory of Signs, Cambridge, Cambridge University Press.

SKAGESTAD P., (1981), The Road of Inquiry: Charles Peirce's Pragmatic Realism, New York, Columbia University Press.

sокоLоwsкi W., (1997), “The Structure of Peirce's Realism,” Prima Philosophia 10, 77-88.

\section{NOTES}

1. Peirce's position is more radical in that he equates cognizability and being (W 2,208, 1868). The upshot remains the same: namely that we need not and cannot concern ourselves with the uncognizable.

2. When Peirce says that what he means by the "real" is merely a demonstrative sign pointing back to the familiar world (W 4,250,1881), his use of "real" pertains to what is here designated as phenomenal or external reality.

3. References to Peirce, for the most part, follow the standard format: CP for Collected Papers, W for Writings: the Chronological Edition, and EP for The Essential Peirce. References to Peirce's letters to Lady Welby will be henceforth given as (Peirce, letter's year, edition page number).

4. Since my choice of terms binds tightly the notions of reality and truth, it may appear to be at odds with Hookway's view that we can have truth without reality and reality without truth. (See Hookway 1992, 139.) However, from the context, it seems clear that what Hookway means by reality is phenomenal reality. Hence he is right: our ultimate conception of reality may contain elements to which no external experience corresponds (e.g. moral ideals), and there will be parts of our experience that will never gain sufficient resolution to be counted as part of a determinate conception.

5. Italics are mine.

6. For discussion see Magada-Ward (2003, 220). 
7. References to Kant are given by work and section number, following the Academy edition. Critique of Judgment is abbreviated as $\mathrm{CJ}$, and follows the translation by Werner Pluhar (Hackett, 1987).

8. My use of the term "subject matter" is meant to closely resemble what Gadamer means by Sache, i.e., the thing that we are talking about, the shared topic of a communicative episode.

9. Or even oneself at a later time.

10. Peirce uses the expression "subject of discourse" to mark that which is designated by an index (W 5,224, 1885). My use of "provisional identification" is intended to resemble what is sometimes referred to as a "passing theory."

11. Peirce thought that correspondence may be useful in producing a sense, however, vague of what approximately may be meant by truth (CP 8.100, 1900). However, when taken literally it does result in useless obfuscation (CP 1.578, 1902; CP 7.370, 1902; CP 5.553, 1906).

\section{AUTHOR}

\section{SERGE GRIGORIEV}

Ithaca College, NY

sgrigoriev[at]ithaca.edu 